\title{
The Impact of Teachers' Collegiality on their Organizational Commitment in High- and Low-Achieving Secondary Schools in Islamabad, Pakistan
}

\author{
Madiha Shah \\ Faculty of Education, University of Malaya \\ 50603, Kuala Lumpur, Malaysia \\ Tel: 60-17-668-4735Ｅ-mail: madihashah.phd@gmail.com
}

Received: March 9, 2011 Accepted: March 28, 2012 Published: May 1, 2012

doi:10.5296/jse.v2i2.1493 URL: http://dx.doi.org/10.5296/jse.v2i2.1493

\begin{abstract}
This paper presents a study on the impact of teachers' collegiality on their organizational commitment in high- and low-achieving secondary schools in Islamabad, Pakistan. The study also examined the differences in teacher collegiality and teacher organizational commitment in the two school-types. The study surveyed 364 public secondary school teachers from 17 schools in Islamabad. Data were analyzed using structural equation modeling (SEM) with AMOS 16.0 and latent mean structure statistics. The analyses confirmed that teacher collegiality positively affected their organizational commitment, but the differences in teacher collegiality were found to be non-significant between the two school-types.
\end{abstract}

Keywords: Teacher collegiality, Organizational commitment, Secondary schools, Teachers, Pakistan. 


\section{Introduction}

Strong collegial relationships among school teachers have consistently been highlighted as an important factor for school improvement and success (DuFour, 2004; Little et al., 2003). The literature on school effectiveness shows that the most promising strategy for sustained, substantive school improvement is developing the ability among school personnel to function as professional collegial communities (Goldenberg, 2004; Joyce, 2004).

The negative effects caused by the psychological isolation that characterized most schools (Bruffee, 1999; Heider, 2005) have also accelerated the adoption of a collegial approach in schools' cultures and shifted the emphasis from individual efforts to group work, from independence to interdependence. Educators are being encouraged to act as team players in order to bring effective learning outcomes for students and management effectiveness for school organizations.

Similarly, organizational commitment has also been identified as a crucial factor in determining and influencing organizational outcomes. It is believed to be vital for organizational productivity, quality, and performance. Higher organizational commitment among school staff influences the future success of education and schools (Huberman, 1993). Teacher commitment to school is thought to impact teachers' work performance as well as student achievement (Chughtai \& Zafar, 2006; Tsui \& Cheng, 1999).

\section{Literature Review}

\subsection{Teacher Collegiality}

The term collegiality refers to the cooperative relationships among colleagues. However, the exact meaning of the term remains conceptually vague in the literature. It is often used interchangeably with 'collaboration'. Jarzabkowski (2002), however, tries to differentiate between collegiality and collaboration by defining collegiality as teachers' involvement with their peers on any level, be it intellectual, moral, political, social, and/or emotional. According to her, collegiality encompasses both professional and social/emotional interaction in the workplace while collaboration mostly relates to the professional sphere of relationships.

The conception that educators perform better when working together professionally is supported by organizational theory models which emerged earlier in the corporate sector (see e.g., Covey, 1991; Senge, 1990). Such conceptions view authentic teamwork as an essential characteristic of the successful organization as its members interact regularly to share their ideas and expertise and develop common understanding of organizational goals and the means of attaining them (Leonard \& Leonard, 2003).

Strengthening interpersonal relations among teaching personnel is thought to influence school professional culture and leads to increased involvement and ownership among teachers (Andrews \& Lewis, 2002). It also plays a significant role in improving teaching and instructional practices and fostering innovation (Brownell et al., 2006; Zhao et al., 2002). Other studies that report positive outcomes of teacher collegiality include more positive 
attitudes toward teaching (Brownell et al., 1997), enhanced job satisfaction (Woods \& Weasmer, 2002), reduced stress and burnout (Numeroff, 2005), improved efficacy (Shachar \& Shmuelevitz, 1997), high morale (Nias, 1999), professional growth and development (Knapp, 2003), reduced staff turnover (Jarzabkowski, 2003), assistance to new and beginning teachers (Wang, Odell, \& Schwille, 2008), and increased levels of trust (Tschannen-Moran, 2001).

Retallick and Butt (2004) studied the workplace relationships of Canadian teachers with their peers in relation to their professional well-being and learning. They assert that healthy peer inter-collegial relations are characterized by positive encouragement, support, sharing, recognition, trust, and mutual respect and caring for each other. Teachers who perceived positive peer relationships in their workplace felt comfortable seeking professional help from their peers. The communication among them was fluid, continuous, informal, and embedded in rich workplace interaction and learning. These teachers were involved in coaching, mentoring, being role models for observation, effective work teams, action research, critical dialogue, and collegial problem solving. Their study concluded that the impact of collegiality resulted in a good level of job satisfaction, commitment, and positive attitudes towards students, teaching, learning, and one's peers.

A study conducted by Huang (2006) examining collegiality among secondary science teachers suggests that teachers in Taiwan had generally favorable perceptions about their inter-personal relations with peers. Teachers of his study valued collegiality and expressed their enjoyment in supporting, encouraging, and cooperating with their peers. They did not prefer to stay in their classrooms all the time. Instead, teachers teaching the same subject shared a common office, an arrangement that promoted healthy collegial interactions and better communication. Teachers felt comfortable in giving comments on each others' practice, discussing their students' progress, and learning from each other particularly during in-service training.

Farah et al. $(1996,1997)$ provide an interesting discussion about the concept of collegiality in the Pakistani context. Their study focusing on rural public primary schools of all four major provinces in Pakistan indicates that teachers in collegial schools have personal as well as professional relationship with each other. Teachers were observed to be convivial. They conversed with one another, preferred to have lunch in groups, came to school together, and even visited each other's homes. They helped each other in school-related work and solved both administrative and instructional problems jointly. They felt comfortable in seeking help on instructional as well as classroom management issues. The study claimed that strong collegiality among teachers was one of the recurring elements found in all the high-performing schools. The researchers, therefore, suggested that school administration should encourage their staff to become learning communities so that the participants could bring valuable knowledge to the school setting and exercise joint problem-solving and teamwork techniques.

Another study conducted by Rizvi and Elliot (2005) on government primary schools in Karachi, illustrates that teachers in schools where reforms had been initiated showed greater 
collaboration for planning and teaching. According to their study, the major aspects of teacher collaboration in Pakistani schools include joint discussions on teaching issues, joint reflection on teaching practices, coordination to plan effective lessons, learning new teaching approaches together, and involvement in collective administrative work.

However, a recent study conducted by Sarwar, Aslam, and Rasheed (2010) highlighted the lack of effective communication and collegial support among senior and junior faculty members in higher education institutions in Pakistan. They claimed that the internal culture of the selected universities and colleges of their study was individual oriented. The faculties lacked team oriented approach to perform various tasks. Therefore, the researchers implied a need for developing a collegial working environment in higher education institutions and suggested that some platforms for teachers to work collectively must be built in order to enhance team oriented culture where all faculty members could perform collectively for institutional development.

\subsection{Organizational Commitment}

Organizational commitment of an individual refers to one's sense of belonging and desire to work hard and contribute to the fullest to the employing organization (Ketchand \& Strawser, 2001). Most researchers agree that no consensus has been reached on the definition of organizational commitment and therefore, the literature is replete with a variety of definitions of organizational commitment. As Yoon and Thye (2002) state, it may be because the term is a broad-ranging concept that cuts across many organizational and sociological domains. However, the variety of definitions for organizational commitment - with all its different measures - shares a common notion that organizational commitment is a bond of the individual to his/her organization (Camilleri, 2006). The accepted definitions of organizational commitment include an identity with the organization, shared goals and values between the individual and the organization, and continuing membership in the organization (Meyer \& Allen, 1991). Employees are regarded as committed to their organization if they willingly continue their association with the organization and devote considerable effort to attain organizational goals (Mowday, 1998; Raju \& Srivastava, 1994).

Employees' commitment to the workplace is also considered a hallmark of organizational success. The concept of organizational commitment was initiated in the early 1950s. Most of the earlier research on organizational commitment was focused on defining the concept, identifying the factors that caused its formation among individuals, and how it influenced organizational consequences after being formed. However, recent research in organizational psychology and organizational behavior literature has examined organizational commitment through two popular approaches, commitment-related attitudes and commitment-related behaviors. Most of the recent research on organizational commitment is more focused on identifying the existence of its multiple dimensions and finding the relationships of these dimensions and sub-dimensions with important antecedents, correlates, and consequences.

Organizational commitment has been given little attention in educational research; however, it is considered as a key facet of a school's capacity for reform and renewal (Geijsel et al., 2003). Chughtai and Zafar (2006) found organizational commitment to be negatively 
correlated to turnover intentions and positively related to job performance among Pakistani university teachers. Similarly, Warsi, Fatima, and Sahibzada (2009) claimed that organizational commitment is strongly and positively influenced by job-related variables such as job satisfaction and work motivation among private sector employees in Pakistan.

\subsection{Impact of teacher collegiality on teacher organizational commitment}

Many researchers have studied the link between collegiality and commitment in the educational settings and claimed that collegiality is positively associated with teacher commitment (see e.g. Barth, 1999; Singh \& Billingsley, 1998; Troncoso-Skidmore, 2007). The literature on teacher culture indicates that in schools where teachers work together to plan school improvement, select instructional methods and activities, and plan teacher professional development and training, teachers tend to be more committed to their organization (Graham, 1996; Mutchler, 2005). Hargreaves (1997) also supports the view that collegiality among teaching personnel helps them to better develop higher commitment levels. Mutchler (2005) claims that teachers' relationship with their colleagues is the most influential factor in teachers' willingness to remain committed to a specific school organization. According to Troncoso-Skidmore (2007), organizational commitment can be nurtured and developed in a collegial school culture.

\subsection{Teacher collegiality and student achievement}

Teacher collegiality is hypothesized to have a strong association with student achievement (Bolam et al., 2005; Goddard et al., 2007; Leana \& Pil, 2006). Research literature on education reform and school improvement suggests that improved student performance may be fully realized only when teachers routinely function as teams and abandon their traditional norms of isolationism and individualism (Leonard \& Leonard, 2003). Teacher collegiality is regarded as one of the most common attributes found in all successful and effective schools. Successful schools can be differentiated from less successful schools by establishing time for teacher talk, teacher observation, and teachers teaching each other (Campo, 1993). It is believed that higher collegial relations among teaching staff lead to higher quality instruction and, in turn, increased student academic achievement (Schmoker, 1999).

Louis and Marks (1998) from their research found that though collegiality was related strongly with the social support for achievement and authentic pedagogy, it had no direct effect on student achievement. Similarly, the research conducted by Supovitz (2002) also supports the view that collegiality cannot be linked directly to improved student achievement. Supovitz and Christman (2003) stated that the link between greater teacher collegiality and improved student academic achievement was not as direct as initially believed. Interventions designed to improve teamwork and communication among teachers, fostering sharing of best practices, and strengthening teacher relationships did not necessarily translate into more effective teaching and better student performance.

\subsection{Teacher organizational commitment and student achievement}

Research examining the relationship between teacher organizational commitment and student achievement suggests that teachers committed to their schools engaged in behavior that lead 
them to achieve school goals and enhance students' achievement. Kushman (1992) found a positive correlation between teacher organizational commitment and student achievement in urban elementary and middle schools. Hoy and Woolfolk (1993) also suggest that higher organizational commitment is related to higher student academic achievement. Reyes and Fuller (1995) studied communal schools which fostered shared values among employees; they indicated that high teacher commitment to school was related to students' mathematics achievement in middle and high schools.

\section{Research Problem}

Although the concept of teacher collegiality has received much attention from educational scholars and researchers in recent years, there is a paucity of research on this topic in developing countries such as Pakistan. Literature review shows that most of the studies on teacher collegiality have been conducted in the United States. Their findings can neither be generalized to the developing world's situation, nor can their implications be applicable to educational institutions in developing countries due to differences in terms of contexts and settings.

Teachers in Pakistan's public educational sector are still struggling in isolation to educate large groups of learners and have fewer resources to help them (Riaz, 2008; Rizvi \& Elliot, 2005). Teachers exhibit poor morale and less committed behavior resulting in high absenteeism, dissatisfaction, and high levels of burnout (Warwick \& Reimers, 1995). According to the EFA 2000 Country Assessment Report for Pakistan, the majority of teachers in the public sector are neither motivated nor committed to the teaching profession.

The review of literature found that most of the studies on teacher collegiality had often been conducted in primary or elementary schools (Rosenholtz, 1989; Zahorik, 1987), although its importance is much more evident at the secondary level. Secondary schools are more complex organizations where teachers may collaborate closely with a small group of colleagues, and have very little to do with faculty working in other departments of the school. Collegiality among secondary school teachers is also regarded as more beneficial as these teachers have little control over the whole task of educating students and their work is often fractionalized, with little coordination across subject areas and little knowledge and responsibility for comprehensive student learning (Boyer, 1983; Goodlad, 1984).

\section{Purpose of the Study}

The main purpose of this study was to identify the impact of teachers' collegiality on their organizational commitment in high-achieving and low-achieving public secondary schools in Islamabad, Pakistan. The study also determined if the impact of teacher collegiality on teacher organizational commitment was equivalent across the two groups (i.e., high-achieving school teachers versus low-achieving school teachers). It further comparatively identified the differences in teacher collegiality and teacher organizational commitment between high-achieving and low-achieving secondary schools.

The research questions that guided this study were: (a) What is the impact of teacher collegiality on teacher organizational commitment in high-achieving and low-achieving 
public secondary schools of Islamabad?; (b) Does school type based on achievement act as a moderator for the impact of teacher collegiality on teacher organizational commitment?; (c) What are the differences in teacher collegiality and teacher organizational commitment between high-achieving and low-achieving public secondary schools in Islamabad?

\section{Methodology}

\subsection{Research Design}

The current study is a quantitative, non-experimental, cross sectional research where survey was used as a major source of data collection. This research design was chosen for the present inquiry because it allows predictions in a large sample with limited resources.

\subsection{Sample and Participant Selection}

Teachers of public secondary schools (both male and female) from across the federal capital district of Islamabad served as research sample. The selection of high-achieving and low-achieving schools was based on their students' secondary school certification (SSC) results on the Federal Board of Intermediate and Secondary Education (FBISE) examination for two concurrent school years, namely 2008 and 2009. The following criteria were used:

- $\quad$ High-achieving schools were those listed schools where $100 \%$ of the students had passed the SSC Annual examination and more than 50\% of the students had achieved either A-1 or A grade. The results were checked for the 2009 SSC Annual examination and then rechecked for the previous school year that is 2008 .

- Low-achieving schools were those listed schools where (1) at least $20 \%$ of the students could not pass the SSC Annual examination by either getting compartment (failing in one or more subjects) or had completely failed, and (2) $50 \%$ of the passing students either got $\mathrm{C}$ grade or less than $\mathrm{C}$ grade. The results were checked for the 2009 SSC Annual examination and then rechecked for the previous school year that is 2008 .

\subsection{Data collection procedures}

The survey of teachers was conducted at 17 public secondary schools including eight high-achieving (four male and four female) and nine low-achieving (four male and five female) schools. For the purpose of collecting data, the selected schools were visited personally. Their principals were told about the purpose and nature of the study and asked for formal permission to conduct the study at their respective schools. Upon getting approval from the principals, the survey questionnaires along with the cover letter were distributed to all the teaching staff numbering 445 in total. The cover letter indicated the aim of the research, its significance, and the time required to fill out the questionnaire. It also assured the participants that the information would be collected independent of their organization, that their participation would be voluntary, and their responses would be kept confidential to encourage sincerity and truthfulness in responses. A total of 364 completed questionnaires (a response rate of $81.79 \%$ ) were collected from the selected schools after a period of two weeks for scoring and analyses. 


\subsection{Instrumentation and Measures}

The survey instrument consisted of two measures: Teacher Collegiality Scale (TCS) and Organizational Commitment Scale (OCS).

\subsubsection{Teacher Collegiality Scale (TCS)}

TCS was a self-developed scale consisting of 32-items. It measured seven dimensions of collegiality among secondary school teachers namely: Demonstrating mutual support and trust (6-items); Observing one another teaching (3-items); Joint planning and assessment (6-items); Sharing ideas and expertise (6-items); Teaching each other (4-items); Developing curriculum together (4-items); and Sharing resources (3-items). The Cronbach alpha reliability coefficient for the TCS ranged from .71 to .85 (Shah, 2011).

\subsubsection{Organizational Commitment Scale (OCS)}

The OCS consisting of 18 items was adapted from Meyer, Allen, and Smith (1993) which is the revised version of the Meyer and Allen (1991) Organizational Commitment Questionnaire. This scale measures three forms of employee commitment to an organization: Affective commitment (desire-based); Continuance commitment (cost-based); and Normative commitment (obligation-based). Each scale consists of six items. The Cronbach alpha values for the OCS for the present study ranged from .82 to .88 .

A Likert scale ranging from 1 to 7 ( 1 = strongly disagree; 7 = strongly agree $)$ was used for both the measures.

\subsection{Statistical Analyses}

Data were analyzed using descriptive as well as inferential statistics. However, preliminary analysis was conducted initially which involved the identification of missing data, examination of univariate and multivariate normality, and the detection of univariate and multivariate outliers.

Structural equation modeling (SEM) using AMOS 16.0 was used to analyze the impact of teacher collegiality on teacher organizational commitment. SEM serves purposes similar to multiple regression, but in a more powerful way which takes into account the modeling of interactions, nonlinearities, measurement error, correlated error terms, multiple latent independents each measured by multiple indicators, and one or more latent dependents also each with multiple indicators. Maximum Likelihood Estimation (MLE) - a widely used estimation technique was applied in this SEM analysis.

Multiple-group SEM analysis was performed to determine if school type based on achievement functioned as the moderator for the impact of teacher collegiality on their organizational commitment. Latent mean structure analysis was conducted to determine the differences in the latent variables (i.e., teacher collegiality and teacher organizational commitment) between high-achieving and low-achieving schools.

\section{Results and findings}




\subsection{Demographic Information of the Respondents}

Almost half of the participants were male (49.2\%) and half were female (50.8\%). A total of 196 respondents (53.8\%) taught in high-achieving schools and $168(46.1 \%)$ taught in low-achieving schools. Table 1 shows that more than half of the teachers $(54.7 \%)$ were master's degree holders and 34.9\% were bachelor's degree holders. Only $10.4 \%$ were either MPhil degree holders or PhD holders. Nearly $22 \%$ of the staff had less than five years of teaching experience and $31 \%$ of the teachers had 5-10 years of experience. Almost $47 \%$ of the staff had been teaching for more than 10 years.

Table 1. Demographic features of survey respondents

\begin{tabular}{ll}
\hline Variable/Category & $\boldsymbol{n}(\%)$ \\
\hline Gender & $179(49.2)$ \\
Male & $185(50.8)$ \\
Female & \\
Educational Attainment & $127(34.9)$ \\
Bachelor's Degree & $199(54.7)$ \\
Master's Degree & $38(10.4)$ \\
MPhil/Doctorate & \\
Professional Experience & $80(22.0)$ \\
Less than 5 years & $113(31.0)$ \\
5-10 years & $95(26.1)$ \\
10-15 years & $46(12.6)$ \\
15-20 years & $30(8.2)$ \\
More than 20 years & \\
\hline
\end{tabular}

Note: $N=364$

\subsection{Descriptive Statistics}

For the descriptive analysis, the means and standard deviations for each subscale of the TCS and OCS were calculated (shown in Table 2). Teachers' perceptions regarding their collegiality showed higher mean values for two subscales namely 'demonstrating mutual support and trust' and 'sharing ideas and expertise'. Observing one another teaching subscale showed the lowest mean values. Regarding commitment to school, teachers were found to have higher continuous commitment in both high-achieving as well as low-achieving schools.

\subsection{Results for SEM analysis}

In SEM analysis, the measurement model is tested initially to assess whether the observed indicators are loaded on hypothesized latent variables using confirmatory factor analysis (CFA), which then serves as an input to estimate the structural coefficients between 
constructs or latent variables. A structural model determines if the data fit the hypothesized model depicting the potential causal dependencies between endogenous and exogenous variables.

Table 2. Descriptive statistics of survey questionnaire for high- and low-achieving school teachers

\begin{tabular}{llrcc}
\hline & \multicolumn{2}{c}{ High-Achieving } & \multicolumn{2}{c}{ Low-Achieving } \\
Subscales & N=196 (53.8\%) & N= 168 (46.1\%) \\
& Mean & SD & Mean & SD \\
\hline Teacher Collegiality & & & & \\
Demonstrating mutual support and trust (DMS) & 5.35 & .73 & 5.27 & .45 \\
Observing one another teaching (OT) & 4.03 & .90 & 4.07 & .82 \\
Joint planning and assessment (JPA) & 4.74 & .70 & 4.64 & .49 \\
Sharing ideas and expertise (SIE) & 5.23 & .56 & 5.06 & .45 \\
Teaching each other (TE) & 5.08 & .58 & 4.98 & .56 \\
Developing curriculum together (DC) & 4.63 & .88 & 4.72 & .60 \\
Sharing resources (SR) & 4.87 & .82 & 4.76 & .67 \\
Organizational Commitment & & & & \\
Affective organizational commitment (AOC) & 4.90 & .87 & 4.63 & .65 \\
Continuance organizational commitment (COC) & 5.04 & .61 & 4.74 & .55 \\
Normative organizational commitment (NOC) & 4.81 & .80 & 4.56 & .54 \\
\hline
\end{tabular}

Note: $N=364$

\subsubsection{Measurement Assessment Using CFA}

The present model was over-identified in which the number of estimable parameters was less than the number of data points (i.e., variances and covariances of the observed variables). The unstandardized estimates (as presented in Appendix 1) were found to be statistically significant given C.R. values $>1.96$ using a significance level of .05. Standardized regression weights of each observed variable onto its first-order latent variable and first-order latent variable's loading onto its second-order factor are presented in Appendix 2. Standardized regression weights tend to vary between +1 and -1 . However, the size of the standardized loadings confirms that the indicators are strongly related to their associated constructs and are one indication of construct validity (Hair et al., 2006). Hair and his colleagues (2006) suggest that standardized loading estimates should be at least 0.5 and ideally 0.7 or higher. All the standardized regression weights for the present study were found to be higher than the recommended cutoff value of 0.5 except one path flowing from 'Observing one another teaching (OT)' subscale to its Item 22 (OT22<--- OT). However, OT22 was not deleted from the analysis in order to follow the three-indicator rule which suggests at least three indicators/items per scale. 


\subsubsection{Assessment of Measurement Model Fit}

The goodness-of-fit (GOF) statistics were examined to verify the measurement model. Hair and colleagues (2006) recommend the use of one absolute fit index, one incremental fit index, and the chi-square $\chi^{2}$ result as measures for the overall fit of the model. The $\chi^{2}$ value for the measurement model was significant $(p<.001)$ indicating that the observed sample and the SEM estimated covariance matrices were statistically different, thus indicating problems with the fit. But due to the fact that $\chi^{2}$ test is very sensitive to both sample size and number of observed variables, therefore, it was expected to get significant $p$-value as the present model contained 50 observed variables and sample size was 364 .

The Root Mean Square Error of Approximation (RMSEA) and the Root Mean Square Residual (RMR) were used as absolute fit indices which consider values less than .07 and .08 respectively to demonstrate acceptable fit (Hair et al., 2006). Both RMSEA and RMR for the measurement model were found to be .05 indicating a good fit. The Comparative Fit Index (CFI) and the Tucker-Lewis Fit Index (TLI) were employed in this study as incremental fit indices which consider values greater than .90 associated with a model that fits well (Hair et al., 2006). The CFI and TLI obtained from the analysis of the current measurement model were .89 and .88 respectively, which were both indicative of a little less than adequate fit of the model to the data. Therefore, in order to identify a model that better represented the sample data, the possible areas of misfit were assessed using modification indices (MIs) and residual moments.

The GOF indices for the modified measurement model (as shown in Table 3) yielded a good fit and therefore, further analysis could be conducted as values suggested strong construct validity.

Table 3. Model fit indices for the modified measurement model

\begin{tabular}{|c|c|c|c|c|c|c|c|}
\hline & $\chi^{2}$ & $p$ & $\chi^{2} / \mathrm{df}$ & CFI & TLI & RMR & RMSEA \\
\hline $\begin{array}{l}\text { Criteria for } \\
\text { Good Fit }\end{array}$ & & & $\leq 2.0$ & $\geq .90$ & $\geq .90$ & $\leq .08$ & $\leq .07$ \\
\hline Fit Indices & 1998.21 & .000 & 1.72 & .91 & .90 & .05 & .04 \\
\hline
\end{tabular}

\subsubsection{Structural Model Testing}

The GOF indices for the structural model were appropriate indicating that the data represented the hypothesized model $(\mathrm{CFI}=.91$; TLI $=.90 ; \mathrm{RMSEA}=.04$; and $\mathrm{RMR}=.05)$. The structural path (Organizational_Commitment <--- Teacher_Collegiality), was statistically significant with critical ratio (C.R.) $>1.96$ and $p$-value $<.001$. The standardized path coefficient from teacher collegiality to organizational commitment was estimated to be .81 indicating a strong positive impact of teacher collegiality on teacher commitment to school. This suggests that teachers who perceive their relationships with their peers as cooperative 


\section{Macrothink}

and collegial tend to be more organizationally committed. The structural model (with standardized estimates) as shown in Figure 1 provides support for the direct positive impact of teacher collegiality on teacher organizational commitment.

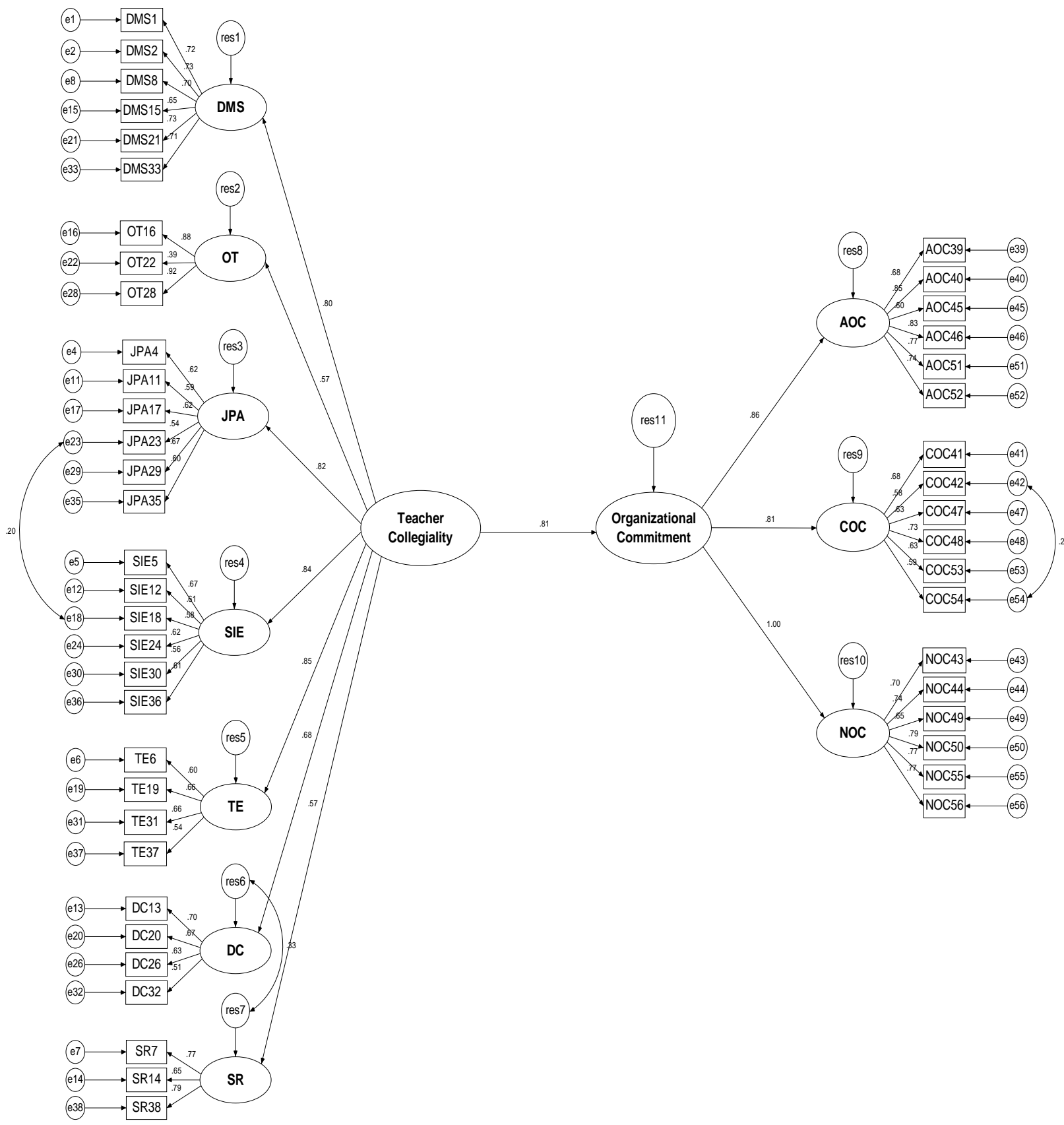

Figure 1. Structural model with standardized estimates.

\subsection{Multiple-group SEM Results}

Multiple-group SEM analysis was performed to determine whether the impact of teachers' collegiality on their organizational commitment was equivalent across the two groups (i.e., high-achieving school teachers versus low-achieving school teachers) and if school type based on achievement functioned as a moderator for this causal relationship. 


\section{Ml Macrothink}

To conduct multi-group SEM analysis, the model was summarized by computing all the observed variables/indicators to their respective factors. The new model was therefore, reduced from second-order factor model to first-order factor model. Both the groups (i.e., high-achieving school teachers and low-achieving school teachers) were tested separately to check for the adequate model fit. Estimation revealed that the model fits the data well for both the groups (high-achieving school teachers: $\chi^{2}(34)=119.17, p=.000$; CFI $=.92$; TLI $=.89$; RMSEA $=.11$ and low-achieving school teachers: $\chi^{2}(34)=61.39, p=.003$; CFI $=.96$; TLI $=.95$; RMSEA $=.07)$. The configural model fit was estimated which provides the baseline value against which all subsequently specified invariance models are compared. The configural invariance for the current model was statistically significant $(p<.001)$ with $\chi^{2}(68)$ $=180.54 ; \mathrm{CFI}=.93 ; \mathrm{TLI}=.91 ;$ and $\mathrm{RMSEA}=.07$.

Table 4. Invariance tests for high-achieving versus low-achieving school teachers

\begin{tabular}{|c|c|c|c|c|c|c|c|c|}
\hline \multirow[t]{2}{*}{ Model Tested } & \multicolumn{4}{|c|}{ Model Fit Measures } & \multicolumn{4}{|c|}{ Model Differences } \\
\hline & $\chi^{2}$ & $\mathrm{df}$ & $p$ & CFI & $\Delta \chi^{2}$ & $\Delta \mathrm{df}$ & $p$ & $\Delta \mathrm{CFI}$ \\
\hline \multicolumn{9}{|l|}{ Separate Groups } \\
\hline $\begin{array}{l}\text { High-Achieving } \\
\text { School Teachers }\end{array}$ & 119.17 & 34 & .000 & .92 & & & & \\
\hline $\begin{array}{l}\text { Low-Achieving } \\
\text { School Teachers }\end{array}$ & 61.39 & 34 & .000 & .96 & & & & \\
\hline $\begin{array}{l}\text { Configural } \\
\text { Invariance }\end{array}$ & 180.54 & 68 & .000 & .93 & & & & \\
\hline $\begin{array}{l}\text { Partial } \\
\text { Measurement } \\
\text { Invariance }\end{array}$ & 189.68 & 73 & .000 & .93 & 9.13 & 5 & NS & .003 \\
\hline $\begin{array}{l}\text { Structural } \\
\text { Invariance }\end{array}$ & 189.68 & 73 & .000 & .93 & 9.13 & 4 & NS & .003 \\
\hline $\begin{array}{lr}\text { Partial } & \text { Structured } \\
\text { Means } & \text { Model } \\
\text { Invariance } & \end{array}$ & 195.67 & 75 & .000 & .93 & 15.12 & 7 & $\mathrm{NS}$ & .005 \\
\hline
\end{tabular}

The partial measurement invariance was performed keeping at least two parameters per construct to assure if the measurement model conducted under different conditions yielded equivalent representations of the same construct. As shown in Table 4, the model with measurement weights constrained revealed an evidence of a well-fitting model. The difference between the CFI values $(\Delta \mathrm{CFI}=.003)$ was found to be less than the recommended cutoff criterion of .01 (Cheung \& Rensvold, 2002) confirming that the measurement model was invariant across the two groups. Once the partial measurement invariance was achieved, the structural invariance was tested. The structural model also yielded $\Delta C F I<.01$; thus, indicating structural invariance across the two groups (shown in Table 4). This result suggests that school type based on achievement does not moderate the impact of teachers' collegiality 
on their organizational commitment among public secondary school teachers in Islamabad. The impact of teacher collegiality on teacher organizational commitment was similar across high-achieving and low-achieving schools.

\subsection{Results for Latent Mean Differences}

In order to determine the mean differences in the latent variables (i.e., teacher collegiality and organizational commitment) between high-achieving and low-achieving school teachers, latent mean structure analysis was conducted. The group of low-achieving school teachers acted as the reference group in which the latent means were fixed to zero to achieve over-identification. The configural model was analyzed and the partial measurement invariance was achieved (as in the previous analysis), equality constrains were imposed on certain parameters (measurement weights as well as the observed variable intercepts). The partial structured means model invariance was then tested. Table 4 indicates that the difference in CFI values for partial structured means model and the configural model was non-significant $(\triangle \mathrm{CFI}<.01)$ concluding that the factor intercepts operated similarly across the two groups and the estimates associated with the current analysis could be interpreted confidently.

The latent mean estimates for high-achieving school teachers are presented in Table 5. The latent factor means for organizational commitment were statistically significant with C.R. > 1.96, whereas latent factor means for teacher collegiality did not show significant difference between the two groups. The positive values for latent mean parameters indicate that high-achieving school teachers have higher levels of commitment to their organization as compared to low-achieving school teachers. The findings of the study suggest that the perceptions of collegiality among secondary school teachers were similar across the two types of schools, thus, indicating no significant influence on student academic achievement. However, teacher organizational commitment acted as a predictor of student performance in Pakistan's secondary schools.

Table 5. Latent mean estimates for structured means model: (High-achieving school teachers)

\begin{tabular}{|c|c|c|c|c|c|}
\hline & Estimate & S.E. & C.R. & $p$ & Label \\
\hline Teacher_Collegiality & .004 & .053 & .080 & .936 & mn_tc \\
\hline Organizational_Commitment & .562 & .123 & 4.552 & $* * *$ & mn_oc \\
\hline
\end{tabular}

Note: $* * *$ indicates $p<.001$.

\section{Discussion and Implications}

Teachers' perceptions regarding their collegiality show that teachers in Islamabad support their colleagues. They trust each other and feel comfortable in sharing their expertise. 
Specifically, teachers do not feel hesitant to ask for suggestions about specific discipline problems and/or discussing classroom management ideas. However, they need to be more open with their colleagues about discussing instructional issues. Similarly, planning teaching strategies together and exercising joint assessment were less obvious among secondary school teachers, which might be due to the restriction of common planning time in most of the schools. Teachers, however, believe that they share knowledge as well as other resources with their peers. The lowest mean values for 'Observing one another teaching' subscale indicate a need of convincing teachers to open their classrooms to their colleagues and to share their teaching practices in order to improve their knowledge and skills. Teachers in Pakistan need to learn that observing each other's practice can improve their teaching skills. Currently, the presence of any other professional in a classroom is viewed as one of scrutiny and surveillance instead of part of professional growth.

Regarding teachers' organizational commitment, the highest mean values for continuance commitment indicate that teachers in Pakistan are more conscious of the costs associated with leaving the organization, which might be due to limited alternatives and opportunities. Teachers showed relatively lower normative commitment which deals with the feeling of obligation to remain with the current employer/employing organization. In Pakistan, public school teachers are hired by the centralized government and not by the school itself. Therefore, many teachers feel obliged to remain committed to the federal educational administration rather than their respective school management. These findings contrast with the earlier research conducted by Tayyab (2006) which showed higher affective and normative commitment than continuance commitment among Pakistani public employees. The difference may be due to the different professional environments.

The present study tested the theories that support the positive impact of teacher collegiality on their organizational commitment (Graham, 1996; Mutchler, 2005; Singh \& Billingsley, 1998; Troncoso-Skidmore, 2007). The results of this study were consistent with the earlier findings indicating that teachers who perceive higher level of collegiality in their schools are most likely to be organizationally committed. This impact was found to be similar across both high-achieving and low-achieving schools indicating that school type based on achievement does not moderate this causal relationship. The non-significant result for multiple-group SEM analysis indicates that collegiality among teaching staff works in a similar way in influencing their organizational commitment levels irrespective of the school type.

This study contradicts the findings of previous research claiming that strong collegial relationship among school staff is positively associated with student achievement (Bolam et al., 2005; Goddard et al., 2007; Leana \& Pil, 2006; Schmoker, 1999). Instead, the present study supports the proposition that collegial relationships in schools do not act as the antecedent or predictor of student achievement. These contradictory results might be due to the fact that most of the previous studies were conducted in the developed world. Moreover, most of these studies did not quantify the levels of teacher collegiality. Rather, they listed collegiality (or teamwork) as a factor repeatedly mentioned by teachers in response to open-ended questions asking teachers or administrators to identify reasons for their schools' success. The studies that quantified teacher collegiality or collaboration did not select schools 
based on prior performance on any achievement test.

Furthermore, studies involving student achievement should not ignore the effects of several other factors such as student personal characteristics, home environment, family income, parent's educational background, and parental involvement. Most specifically, family background variables play a vital role in influencing students' learning outcomes. During the data collection process, it was observed that most of the schools performing low were located in comparatively less advantaged areas. This might have affected the results of the current study. Socio-economic status (SES) is considered as an important factor when student achievement is involved in a research framework.

The present study validates the work of Louis and Marks (1998), Supovitz (2002), Supovitz and Christman (2003), and Little (2006) which found that teacher collegiality could not be linked directly to improved student achievement in schools. These studies further claimed that fostering or strengthening teacher relationships did not necessarily translate into more effective teaching and better student performance. The presence of collegiality among teachers alone does not ensure that teachers will engage in deep discourse of how to improve instruction which ultimately will influence student learning. In order to gain greater benefits from teacher collegiality, the focus of collaboration should include instruction, professional growth, assessment of teaching practices, and strategies for improving school effectiveness. Moreover, students in low-achieving schools might require different instructional and pedagogical styles for effective learning as compared to their counterparts, which may be identified if teachers share information with each other.

Organizational commitment, on the other hand was found to be statistically higher for teachers teaching in high-achieving schools versus low-achieving schools, suggesting a positive association between organizational commitment and student academic achievement. This result supports the findings of Kushman (1992), Hoy and Woolfolk (1993), and Reyes and Fuller (1995) who all found a positive correlation between teacher organizational commitment and student achievement in their respective studies. The relationship between organizational commitment and student achievement could be two-way. High performance of students might help in increasing school commitment among teachers as teachers feel recognized and valued in such schools.

A strong positive impact of teacher collegiality on their organizational commitment necessitates school leadership to focus on improving collegial relationships among their staff if they desire a highly committed staff. Collegiality should be structured and organized to influence teaching and instructional practices which eventually affects student learning. Therefore, principals must provide their teaching staff with sufficient common planning time where consistent and sustained focus on instruction could be placed. The main implication for teachers is the need to recognize the value of working together, to value peer observation, and involve efficiently in activities regarding curriculum development and joint assessment. Teachers must open their classrooms to their colleagues, with the expectation of observing and being observed. They must work together to identify and adapt their own strategies for improving student achievement in their respective schools. 
Teacher collegiality being non-significantly different in two types of schools indicates the presence of other mediating factors. These mediating factors could be pedagogical skills and instructional practices that ultimately influence student learning. For getting enormous benefits from teacher collegiality in schools, teachers need to apprehend how collegiality can act as a tool of instructional improvement and professional development. Higher levels of organizational commitment among teachers can also yield positive outcomes, including high student achievement and school performance. Organizationally committed teachers exert greater efforts for their schools and are willing to take responsibility for the achievement of schools.

\section{Conclusion, Limitations, and Future Research}

Consistent argument in the literature about the contributions of teacher collegiality for augmenting teachers' commitment towards their organization is strongly supported by this study. Collegiality in Pakistan acts as a strong factor in retaining individuals in their organizations. However, the research shows that collegiality among teachers does not always ensure school performance, yet its impact on school effectiveness cannot be denied. Presence of interdependence among teachers is clearly evident in the Pakistani school environment. However, some important elements of teacher collegiality need to be focused and enhanced such as peer observation, joint assessment, and collaborative curriculum development.

The current study is delimited to the teachers of urban public secondary schools of Islamabad. The generalizability of the results from a small sampling - teachers from eight high-achieving and nine low-achieving secondary schools located in a single city is recognized as a limitation. Furthermore, the present study only focuses on teacher- teacher relationships within the school organization, although the concept of collegiality also includes teacher-principal relationships (Barth, 2006; Butt \& Retallick, 2002; Little, 2002). Moreover, this study uses a quantitative approach and data were collected using a self-reporting instrument. Reliance on self-report data could be a limiting factor. The measures used in this study were based on Likert-type responses which do not allow participants to construct their own responses; nor do they allow the researchers to probe to gain additional insight. To fully understand collegiality among school teachers and teachers' commitment to their workplace, educators and researchers need more elaborative studies. Another limitation of the current study is that it focuses on one way effect of collegiality on commitment rather than examining the two-way effect. Higher levels of school commitment among teachers could enhance their interpersonal relationships with peers.

Despite the limitations noted, any association or impact unveiled in this study would advance the notion of collegiality as a viable premise for future research. Furthermore, an educational study of this nature would hopefully contribute to the generation of new ideas and perspectives for increasing school commitment through enhancing interpersonal relations among school personnel. Additional research could include other variables in the model such as administrative support. The role of the school administration and principal leadership plays a vital role in developing, maintaining, and enhancing collegiality among teaching staff (Chance \& Segura, 2009; Numeroff \& Acker-Hocevar, 2005) as well as affecting teacher 
organizational commitment (Ketchand \& Strawser, 2001; Tatlah, Ali, \& Saeed, 2011).

As indicated by the results of this study, teacher collegiality does not always influence student achievement. This shows that there might be some other factors that are linked with student achievement such as external tutoring, SES of student, or student personal factors. Similarly, it is also argued that teacher performance and instructional style sometimes act as intervening variables in such studies (Lee, Smith, \& Croninger, 1995). It is therefore, suggested that further studies on investigating the effect of collegiality on student achievement must include a more comprehensive model of predictors which could allow for a simultaneous analysis of the effect of other mediating factors. Furthermore, to support the quantified data, additional qualitative data should be collected and analyzed to determine the presence of true collegiality among teaching staff rather than staff's predisposition to collaboration. In addition, future research might explore if building on collegiality to include teaching practices and instructional and pedagogical styles impact student achievement.

\section{References}

Andrews, D., \& Lewis, M. (2002). The experience of a professional community: Teachers developing a new image of themselves and their workplace. Educational Research, 44 (3), 237-254. http://dx.doi.org/10.1080/00131880210135340

Barth, R. S. (1999). The teacher leader. Providence, RI: The Rhode Island Foundation.

Barth, R. S. (2006). Improving relationships within the schoolhouse. Educational Leadership, $63(6), 8-13$.

Bolam, R., McMahon, A., Stoll, L., Thomas, S., Wallace, M., Greenwood, A., ... Smith, M. (2005). Creating and sustaining effective professional learning communities, DfES Research Report RR637, University of Bristol. Retrieved from www.dfes.gov.uk/research/data/uploadfiles/RR637.pdf

Boyer, E. L. (1983). High school: A report on secondary education in America. New York, NY: Harper \& Row.

Brownell, M. T., Yeager, E., Rennells, M. S., \& Riley, T. (1997). Teachers working together: What teacher educators and researchers should know. Teacher Education and Special Education, 20 (4), 340-359. http://dx.doi.org/10.1177/088840649702000405

Brownell, M. T., Adams, A., Sindelar, P., Waldron, N., \& Vanhover, S. (2006). Learning from collaboration: The role of teacher qualities. Exceptional Children, 72 (2), 169-187.

Bruffee, K. A. (1999). Collaborative learning: Higher education, interdependence, and the authority of knowledge (2nd ed.). Baltimore, MD: The Johns Hopkins University Press.

Butt, R., \& Retallick, J. (2002). Professional well-being and learning: A study of administrator-teacher workplace relationships. Journal of Educational Enquiry, 3 (1), 17-34.

Camilleri, E. (2006). Towards developing an organizational commitment - public service motivation model for the Maltese public service employees. Public Policy and Administration, 21 (1), 63-83. http://dx.doi.org/10.1177/095207670602100105

Campo, C. (1993). Collaborative school cultures: How principals make a difference. School Organization, 13 (2), 119-126. 
Chance, P. L., \& Segura, S. N. (2009). A rural high school's collaborative approach to school improvement. Journal of Research in Rural Education, 24 (5), 1-12.

Cheung, G. W., \& Rensvold, R. B. (2002). Evaluating goodness-of-fit indexes for testing measurement invariance. Structural Equation Modeling, 9 (2), 233-255. http://dx.doi.org/10.1207/S15328007SEM0902_5

Chughtai, A., \& Zafar, S. (2006). Antecedents and consequences of organizational commitment among Pakistani university teachers. Applied HRM Research 11 (1), 39-64.

Covey, S. R. (1991). Principle-centered leadership. New York, NY: Summit Books.

DuFour, R. (2004). What is a "professional learning community"? Educational Leadership, $61(8), 6-11$.

EFA (2000). Assessment: Pakistan country report. Retrieved from www.unesco.org/education/wef/countryreports/pakistan/rapport_2_2.html

Farah, I., Mehmood, T., Amna., Jaffar, R., Ashams, F., Iqbal, P., ... Gul-Mastoi, N. (1996). Road to Success: Self-sustaining Primary School Change in Rural Pakistan. Report prepared for the World Bank. Karachi: AKU-IED.

Farah, I. (1997). Road to Success (RTS): Phase II, Stakeholders consultation on how primary schools change in rural Pakistan. Report prepared for the World Bank. Karachi: AKU-IED.

Geijsel, F., Sleegers, P., Leithwood, K., \& Jantzi, D. (2003). Transformational leadership effects on teachers' commitment and effort toward school reform. Journal of Educational Administration, 41 (3), 228-256. http://dx.doi.org/10.1108/09578230310474403

Goddard, Y. L., Goddard, R. D., \& Tschannen-Moran, M. (2007). A theoretical and empirical investigation of teacher collaboration for school improvement and student achievement in public elementary schools. Teachers College Record, 109 (4), 877-896.

Goldenberg, C. (2004). Successful school change: Creating settings to improve teaching and learning. New York, NY: Teachers College Press.

Goodlad, J. I. (1984). A place called school: Prospects for the future. New York, NY: MacGraw-Hill.

Graham, K. C. (1996). Running ahead: Enhancing teacher commitment. Journal of Physical Education, Recreation, and Dance, 67 (1), 45-47.

Hair, J. F. Jr., Black, W. C., Babin, B. J., Anderson, R. E., \& Tatham, R. L. (2006). Multivariate data analysis. Upper Saddle River, NJ: Pearson.

Hargreaves, A. (1997). The four ages of professionalism and professional learning. UNICORN, 23 (2), 86-108.

Heider, K. L. (2005). Teacher isolation: How mentoring programs can help. Current Issues in Education [On-line], 8 (14). Retrieved from http://cie.ed.asu.edu/volume8/number14/

Hoy, W. K., \& Woolfolk, A. E. (1993). Teachers' sense of efficacy and the organizational health of schools. Elementary School Journal, 93 (4), 335-372. http://dx.doi.org/10.1086/461729

Huang, Shwu-yong L. (2006). An assessment of science teachers' perceptions of secondary 
school environments in Taiwan. International Journal of Science Education, 28 (1), 25-44.

Huberman, M. (1993). The lives of teachers (J. Neufeld, trans.). London, UK: Cassell.

Jarzabkowski, L. M. (2002). The social dimensions of teacher collegiality. Journal of Educational Enquiry, 3 (2), 1-20.

Jarzabkowski, L. M. (2003). Teacher collegiality in a remote Australian school. Journal of Research in Rural Education, 18 (3), 139-144.

Joyce, B. (2004). How are professional learning communities created? Phi Delta Kappan, 86 (1), 76-83.

Ketchand, A. A., \& Strawser, J. R. (2001). Multiple dimensions of organizational commitment: Implications for future accounting research. Behavioral Research in Accounting, 13 (1), 222-252. http://dx.doi.org/10.2308/bria.2001.13.1.221

Knapp, M. S. (2003). Professional development as a policy pathway. Review of Research in Education, 27 (1), 109-157. http://dx.doi.org/10.3102/0091732X027001109

Kushman, J. W. (1992). The organizational dynamics of teacher workplace commitment: A study of urban elementary and middle schools. Educational Administration Quarterly, 28 (1), 5-42. http://dx.doi.org/10.1177/0013161X92028001002

Leana, C. R., \& Pil, F. K. (2006), Social capital and organizational performance: Evidence from urban public schools. Organization Science, 17 (3), 353-366. http://dx.doi.org/10.1287/orsc.1060.0191

Lee, V. E., Smith, J. B., \& Croninger, R. G. (1995). Another look at high school restructuring. Issues in restructuring schools. Madison, WI: Center on Organization and Restructuring of Schools, School of Education, University of Wisconsin-Madison.

Leonard, L., \& Leonard, P. (2003). The continuing trouble with collaboration: Teachers talk. Current Issues in Education [On-line], 6 (15). Retrieved from http://cie.ed.asu.edu/volume6/number15/

Little J. W. (2002). Assessing the prospects for teacher leadership. In A. Lieberman (Ed.), Building a professional culture in schools (pp. 78-106). New York: Teachers College Press.

Little, J. W. (2006). Professional community and professional development in the learning-centered school. Prepared for the National Education Association.

Little, J. W., Gearhart, M., Curry, M., \& Kafta, J. (2003). Looking at student work for teacher learning, teacher community and school reform. Phi Delta Kappan, 85 (3), 184-192.

Louis, K. S., \& Marks, H. M. (1998). Does professional community affect the classroom? Teachers' work and student experiences in restructuring schools. American Journal of Education, 106 (4), 532-575. http://dx.doi.org/10.1086/444197

Meyer, J. P., \& Allen, N. J. (1991). A three-component conceptualization of organizational commitment. Human Resource Management Review, 1 (1), 61-89. http://dx.doi.org/10.1016/1053-4822(91)90011-Z

Meyer, J. P., Allen, N. J., \& Smith, C. A. (1993). Commitment to organizations and occupations: Extension and test of a three-component conceptualization. Journal of Applied Psychology, 78 (4), 538-551. http://dx.doi.org/10.1037/0021-9010.78.4.538 
Mowday, R. T. (1998). Reflections on the study and relevance of organization commitment. Human Resource Management Journal, 8 (4), 387-401.

Mutchler, S. E. (2005). Teacher commitment in an academically improving, high-poverty public school. Doctoral dissertation, The University of Texas, Austin.

Nias, J. (1999) Teachers' moral purposes: Stress, vulnerability, and strength. In R. Vandenberghe, \& A. M. Huberman (Eds.), Understanding and preventing teacher burnout: a sourcebook of international research and practice (pp. 223-237). Cambridge: Cambridge University Press. http://dx.doi.org/10.1017/CBO9780511527784.015

Numeroff, D. (2005). Teacher collegiality and collaboration in exemplary high school math departments. Doctoral dissertation, Florida Atlantic University, AAT 3162664.

Numeroff, D., \& Acker-Hocevar, M. (2005). Teacher collegiality and distributed leadership in exemplary high school math departments. Paper presented at the annual meeting of the American Education Research Association (April), Montreal, Canada.

Raju, P. M., \& Srivastava, R. C. (1994). Factors contributing to commitment to the teaching profession. International Journal of Educational Management, 8 (5), 7-13. http://dx.doi.org/10.1108/09513549410065684

Retallick, J., \& Butt, R. (2004). Professional well-being and learning: A study of teacher-peer workplace relationships. Journal of Educational Enquiry, 5 (1), 85-99.

Reyes, P., \& Fuller, E. J. (1995). The effects of selected elements of communal schools and middle and high school mathematics achievement. Madison, WI: Center on Organization and Restructuring of Schools. (ERIC Document Reproduction Service No. ED 384 955).

Riaz, I. (2008). Schools for change: a perspective on school improvement in Pakistan. Improving Schools, 11 (2), 143-156. http://dx.doi.org/10.1177/1365480208091106

Rizvi, M., \& Elliot, B. (2005). Teachers' perceptions of their professionalism in government primary schools in Karachi, Pakistan. Asia-Pacific Journal of Teacher Education, 33 (1), 35-52. http://dx.doi.org/10.1080/1359866052000341115

Rosenholtz, S. J. (1989). Workplace conditions that affect teacher quality and commitment: Implications for teacher induction programs. The Elementary School Journal, 89 (4), 421-439. http://dx.doi.org/10.1086/461584

Sarwar, S., Aslam, H. D., \& Rasheed, M. I. (2010). Hindering factors of beginning teachers' high performance in higher education Pakistan - A case study of IUB - The Islamia University of Bahawalpur. International Journal of Education, 2 (1): E9.

Schmoker, M. (1999). Results: The key to continuous school improvement (2nd ed.). Alexandria, VA: Association for Supervision and Curriculum Development.

Senge, P. (1990). The fifth discipline. New York, NY: Doubleday.

Shachar, H., \& Shmuelevitz, H. (1997). Implementing cooperative learning, teacher collaboration and teacher's sense of efficacy in heterogeneous junior high schools. $\begin{array}{lllll}\text { Contemporary } & \text { Educational } & \text { Psychology, } & 22 & \text { (1), }\end{array}$ http://dx.doi.org/10.1006/ceps.1997.0924

Shah, M. (2011). The dimensionality of teacher collegiality and the development of teacher 
collegiality scale. International Journal of Education, 3 (2): E10. http://dx.doi.org/10.5296/ije.v3i2.958

Singh, K., \& Billingsley, B. S. (1998). Professional support and its effects on teachers' commitment. Journal of Educational Research, 91 (4), 229-239. http://dx.doi.org/10.1080/00220679809597548

Supovitz, J. A. (2002). Developing communities of instructional practice. Teachers College Record, 104 (8), 1591-1626. http://dx.doi.org/10.1111/1467-9620.00214

Supovitz, J. A., \& Christman, J. B. (2003). Developing communities of instructional practice: Lessons from Cincinnati and Philadelphia. CPRE Policy Briefs, 1-10.

Tatlah, I. A., Ali, Z., \& Saeed, M. (2011). Leadership behavior and organizational commitment: An empirical study of educational professionals. International journal of Academic Research, 3 (2), 1293-1298.

Tayyab, S. (2006). Antecedents and consequences of organizational commitment in Pakistan. Doctoral dissertation, Quaid-i-Azam University, Islamabad.

Troncoso-Skidmore, S. (2007, February). Professionally committed teachers. PRISE White Paper No. 2007-9.

Tschannen-Moran, M. (2001). Collaboration and the need for trust. Journal of Educational Administration, 39 (4), 308-331. http://dx.doi.org/10.1108/EUM0000000005493

Tsui, K. T., \& Cheng, Y. C. (1999). School organizational health and teacher commitment: A contingency study with multi-level analysis. Educational Research and Evaluation 5 (3), 249-268. http://dx.doi.org/10.1076/edre.5.3.249.3883

Wang, J., Odell, S. J., \& Schwille, S. A. (2008). Effects of teacher induction on beginning teachers' teaching: A critical review of the literature. Journal of Teacher Education, 59 (2), 132-152. http://dx.doi.org/10.1177/0022487107314002

Warsi, S., Fatima, N., \& Sahibzada, S. A. (2009). Study on relationship between organizational commitment and its determinants among private sector employees of Pakistan. International Review of Business Research Papers 5 (3), 399-410.

Warwick, D. P., \& Reimers, F. (1995). Hope or Despair? Learning in Pakistan's Primary Schools. Westport, CT: Praeger Publishers.

Woods, A. M., \& Weasmer, J. (2002). Maintaining job satisfaction: Engaging professionals as active participants. The Clearing House, 75 (4), 186-189. http://dx.doi.org/10.1080/00098650209604928

Yoon, J., \& Thye, S. (2002). A dual process model of organizational commitment, job satisfaction and organizational support. Work and Occupations, 29 (1), 97-124. http://dx.doi.org/10.1177/0730888402029001005 


\section{Macrothink}

Journal of Studies in Education

ISSN 2162-6952 2012, Vol. 2, No. 2

Zahorik, J. A. (1987). Teachers' collegial interactions: An exploratory study. The Elementary School Journal, 87 (4), 385-396. http://dx.doi.org/10.1086/461503

Zhao, Y., Pugh, K., Sheldon, S., \& Byers, J. (2002). Conditions for classroom technology innovations. Teachers College Record, $104 \quad$ (3), 482-515. http://dx.doi.org/10.1111/1467-9620.00170

\section{Acronyms}

DMS = Demonstrating mutual support and trust; OT = Observing one another teaching; JPA $=$ Joint planning and assessment; SIE $=$ Sharing ideas and expertise; $\mathrm{TE}=$ Teaching each other; $\mathrm{DC}=$ Developing curriculum together; $\mathrm{SR}=$ Sharing resources; $\mathrm{AOC}=$ Affective organizational commitment; $\mathrm{COC}=$ Continuance organizational commitment; $\mathrm{NOC}=$ Normative organizational commitment; res = residual error term; $\mathrm{e}=$ error

\section{Appendix}


Appendix 1. Unstandardized regression weights of CFA model

Estimate S.E. C.R. P Label

\begin{tabular}{|c|c|c|c|c|c|}
\hline DMS & $<---$ Teacher_Collegiality & .983 & .111 & 8.866 & $* * *$ \\
\hline OT & $<---$ Teacher_Collegiality & .974 & .118 & 8.224 & $* * *$ \\
\hline JPA & $<---$ Teacher_Collegiality & 1.000 & & & \\
\hline SIE & $<---$ Teacher_Collegiality & .942 & .118 & 7.965 & $* * *$ \\
\hline TE & $<---$ Teacher_Collegiality & 1.206 & .141 & 8.526 & $* * *$ \\
\hline $\mathrm{DC}$ & $<---$ Teacher_Collegiality & .970 & .133 & 7.267 & $* * *$ \\
\hline SR & $<---$ Teacher_Collegiality & .914 & .131 & 6.966 & $* * *$ \\
\hline $\mathrm{AOC}$ & $<---$ Organizational_Commitment & 1.164 & .137 & 8.523 & $* * *$ \\
\hline $\mathrm{COC}$ & $<---$ Organizational_Commitment & 1.000 & & & \\
\hline NOC & $<---$ Organizational_Commitment & 1.516 & .164 & 9.268 & $* * *$ \\
\hline DMS33 & $<---$ DMS & 1.103 & .088 & 12.569 & $* * *$ \\
\hline DMS21 & $<---$ DMS & 1.491 & .117 & 12.781 & $* * *$ \\
\hline DMS15 & $<---$ DMS & .935 & .084 & 11.171 & $* * *$ \\
\hline DMS8 & $<---$ DMS & 1.000 & & & \\
\hline DMS2 & $<---$ DMS & 1.271 & .100 & 12.657 & $* * *$ \\
\hline DMS1 & $<---$ DMS & 1.110 & .089 & 12.497 & $* * *$ \\
\hline OT28 & $<---$ OT & 1.025 & .053 & 19.235 & $* * *$ \\
\hline OT22 & $<---$ OT & .686 & .084 & 8.210 & $* * *$ \\
\hline OT16 & $<---$ OT & 1.000 & & & \\
\hline JPA35 & $<---\quad$ JPA & 1.038 & .116 & 8.924 & $* * *$ \\
\hline JPA29 & $<---\quad$ JPA & 1.170 & .121 & 9.639 & $* * *$ \\
\hline JPA23 & $<---\quad$ JPA & .883 & .104 & 8.467 & $* * *$ \\
\hline JPA17 & $<---\quad$ JPA & 1.049 & .115 & 9.141 & $* * *$ \\
\hline JPA11 & $<---\quad$ JPA & 1.000 & & & \\
\hline JPA4 & $<---\quad$ JPA & 1.193 & .130 & 9.160 & $* * *$ \\
\hline SIE36 & $<---$ SIE & .879 & .096 & 9.108 & $* * *$ \\
\hline SIE30 & $<---$ SIE & .732 & .086 & 8.473 & $* * *$ \\
\hline SIE24 & $<---$ SIE & 1.079 & .117 & 9.193 & $* * *$ \\
\hline SIE18 & $<---\quad$ SIE & 1.000 & & & \\
\hline SIE12 & $<---$ SIE & 1.129 & .125 & 9.060 & $* * *$ \\
\hline SIE5 & $<---$ SIE & 1.002 & .104 & 9.671 & $* * *$ \\
\hline TE37 & $<---$ TE & .707 & .082 & 8.650 & $* * *$ \\
\hline TE31 & $<---\quad \mathrm{TE}$ & 1.000 & & & \\
\hline TE19 & $<---$ TE & .883 & .088 & 10.054 & $* * *$ \\
\hline TE6 & $<---\quad \mathrm{TE}$ & .746 & .080 & 9.278 & $* * *$ \\
\hline
\end{tabular}


Estimate S.E. C.R. P Label

\begin{tabular}{|c|c|c|c|c|}
\hline DC32<--- DC & .928 & .122 & 7.589 & $* * *$ \\
\hline DC26 <--- DC & 1.000 & & & \\
\hline DC20 <--- DC & 1.273 & .137 & 9.314 & $* * *$ \\
\hline DC13<--- DC & 1.118 & .117 & 9.553 & $* * *$ \\
\hline SR38<--- SR & .998 & .089 & 11.238 & $* * *$ \\
\hline SR14<--- SR & 1.000 & & & \\
\hline SR7 <--- SR & .988 & .089 & 11.108 & $* * *$ \\
\hline AOC39<--- AOC & 1.397 & .132 & 10.608 & $* * *$ \\
\hline AOC40<--- AOC & 1.630 & .131 & 12.453 & $* * *$ \\
\hline AOC45<--- AOC & 1.000 & & & \\
\hline AOC46<--- AOC & 1.510 & .124 & 12.201 & $* * *$ \\
\hline AOC51<--- AOC & 1.453 & .125 & 11.66 & $* * *$ \\
\hline AOC52<--- AOC & 1.319 & .116 & 11.365 & $* * *$ \\
\hline $\mathrm{COC} 41<---\mathrm{COC}$ & 1.058 & .103 & 10.277 & $* * *$ \\
\hline $\mathrm{COC} 42<---\mathrm{COC}$ & 1.053 & .108 & 9.706 & $* * *$ \\
\hline $\mathrm{COC} 47<---\mathrm{COC}$ & 1.000 & & & \\
\hline COC $48<---$ COC & 1.289 & .118 & 10.922 & $* * *$ \\
\hline COC53<--- COC & 1.078 & .108 & 9.969 & $* * *$ \\
\hline COC54<--- COC & 1.022 & .104 & 9.825 & $* * *$ \\
\hline NOC43<--- NOC & 1.097 & .093 & 11.828 & $* * *$ \\
\hline NOC44<--- NOC & .905 & .074 & 12.248 & $* * *$ \\
\hline NOC49<--- NOC & 1.000 & & & \\
\hline NOC50<--- NOC & 1.254 & .097 & 12.942 & $* * *$ \\
\hline NOC55<--- NOC & 1.194 & .095 & 12.632 & $* * *$ \\
\hline NOC56<--- NOC & 1.126 & .088 & 12.725 & $* * *$ \\
\hline
\end{tabular}

Note: $* * *$ shows significance at $\mathrm{p}<.001$. 
Appendix 2. Standardized regression weights of CFA model

\begin{tabular}{|c|c|c|c|}
\hline & & & Estimate \\
\hline DMS & $<---$ & Teacher_Collegiality & .793 \\
\hline OT & $<---$ & Teacher_Collegiality & .576 \\
\hline JPA & $<---$ & Teacher_Collegiality & .828 \\
\hline SIE & $<---$ & Teacher_Collegiality & .832 \\
\hline $\mathrm{TE}$ & $<---$ & Teacher_Collegiality & .841 \\
\hline DC & $<---$ & Teacher_Collegiality & .706 \\
\hline SR & $<---$ & Teacher_Collegiality & .591 \\
\hline $\mathrm{AOC}$ & $<---$ & Organizational_Commitment & .862 \\
\hline $\mathrm{COC}$ & $<---$ & Organizational_Commitment & .789 \\
\hline NOC & $<---$ & Organizational_Commitment & 1.000 \\
\hline DMS33 & $<---$ & DMS & .714 \\
\hline DMS21 & $<---$ & DMS & .730 \\
\hline DMS15 & $<---$ & DMS & .651 \\
\hline DMS8 & $<---$ & DMS & .700 \\
\hline DMS2 & $<---$ & DMS & .730 \\
\hline DMS1 & $<---$ & DMS & .719 \\
\hline OT28 & $<---$ & $\mathrm{OT}$ & .923 \\
\hline OT22 & $<---$ & OT & .393 \\
\hline OT16 & $<---$ & OT & .881 \\
\hline JPA35 & $<---$ & JPA & .592 \\
\hline JPA29 & $<---$ & JPA & .666 \\
\hline JPA23 & $<---$ & JPA & .529 \\
\hline JPA17 & $<---$ & JPA & .613 \\
\hline JPA11 & $<---$ & JPA & .590 \\
\hline JPA4 & $<---$ & JPA & .615 \\
\hline SIE36 & $<---$ & SIE & .607 \\
\hline SIE30 & $<---$ & SIE & .562 \\
\hline SIE24 & $<---$ & SIE & .621 \\
\hline SIE18 & $<---$ & SIE & .585 \\
\hline SIE12 & $<---$ & SIE & .610 \\
\hline SIE5 & $<---$ & SIE & .676 \\
\hline TE37 & $<---$ & $\mathrm{TE}$ & .541 \\
\hline TE31 & $<---$ & $\mathrm{TE}$ & .657 \\
\hline TE19 & $<---$ & $\mathrm{TE}$ & .654 \\
\hline TE6 & $<---$ & $\mathrm{TE}$ & .599 \\
\hline DC32 & $<---$ & DC & .503 \\
\hline
\end{tabular}




\begin{tabular}{|c|c|c|c|}
\hline & & & Estimate \\
\hline DC26 & $<---$ & $\mathrm{DC}$ & .623 \\
\hline DC20 & $<---$ & $\mathrm{DC}$ & .678 \\
\hline DC13 & $<---$ & $\mathrm{DC}$ & .698 \\
\hline SR38 & $<---$ & SR & .796 \\
\hline SR14 & $<---$ & SR & .657 \\
\hline SR7 & $<---$ & SR & .767 \\
\hline AOC39 & $<---$ & $\mathrm{AOC}$ & .677 \\
\hline $\mathrm{AOC} 40$ & $<---$ & $\mathrm{AOC}$ & .855 \\
\hline AOC45 & $<---$ & $\mathrm{AOC}$ & .602 \\
\hline $\mathrm{AOC} 46$ & $<---$ & $\mathrm{AOC}$ & .828 \\
\hline AOC51 & $<---$ & $\mathrm{AOC}$ & .775 \\
\hline AOC52 & $<---$ & $\mathrm{AOC}$ & .745 \\
\hline COC41 & $<---$ & $\mathrm{COC}$ & .663 \\
\hline COC42 & $<---$ & $\mathrm{COC}$ & .621 \\
\hline COC47 & $<---$ & $\mathrm{COC}$ & .629 \\
\hline COC48 & $<---$ & $\mathrm{COC}$ & .720 \\
\hline COC53 & $<---$ & $\mathrm{COC}$ & .638 \\
\hline COC54 & $<---$ & $\mathrm{COC}$ & .628 \\
\hline NOC43 & $<---$ & NOC & .704 \\
\hline NOC44 & $<---$ & NOC & .737 \\
\hline NOC49 & $<---$ & NOC & .652 \\
\hline NOC50 & $<---$ & NOC & .786 \\
\hline NOC55 & $<---$ & NOC & .767 \\
\hline NOC56 & $<---$ & NOC & .768 \\
\hline
\end{tabular}

